\title{
EM Fields Generated by a Scale Model Helical Antenna and Its Use in Validating a Code for Lightning-Induced Voltage Calculation
}

\author{
Massimo Brignone ${ }^{\circledR}$, Member, IEEE, Daniele Mestriner ${ }^{\circledR}$, Student Member, IEEE, \\ Renato Procopio (1), Senior Member, IEEE, Mansueto Rossi, Member, IEEE, \\ Alexandre Piantini ${ }^{\circledR}$, Senior Member, IEEE, and Farhad Rachidi ${ }^{\circledR}$, Fellow, IEEE
}

\begin{abstract}
This paper aims at validating a code for the evaluation of lightning-induced overvoltages developed in the PSCADEMTDC environment using experimental results obtained on an experimental facility deployed at the University of São Paulo, Brazil that emulates the return stroke channel with a helical antenna. For this reason, suitable expressions for the helix electromagnetic fields are presented and conditions under which they can be approximated with the ones produced by the classical lightning channel model (i.e., a vertical antenna) are derived. Moreover, the analysis of the deviations between measurements and calculations is used as a tool to propose a channel vertical coordinate dependent function for the speed that guarantees the best fitting. The validation is done considering different line configurations, from a single line to a complex layout with one main feeder and many laterals and in the presence of non-linear elements, such as surge arresters.
\end{abstract}

Index Terms-Lightning electromagnetic pulse, lightning induced effects and protection, lightning location, lightning measurement and modeling.

\section{INTRODUCTION}

$\mathbf{L}$ IGHTNING strikes are one of the major causes of overvoltages and faults in transmission and distribution systems. As well known, lightning overvoltages are mainly divided into two categories: those due to a direct strike and those induced by nearby lightning (indirect strikes) [1].

Direct strikes to line conductors occur when they intercept a descending lightning leader through a connecting upward discharge within an interception radius commonly called attractive radius (e.g., [2]). Indirect strikes occur when descending lightning leaders are not intercepted by the line conductors and

Manuscript received June 18, 2018; revised December 13, 2018, February 19, 2019, and April 5, 2019; accepted April 15, 2019. (Corresponding author: Daniele Mestriner.)

M. Brignone and R. Procopio are with the ICT and Electrical Engineering Department (DITEN), University of Genoa, Genova I-16145, Italy (e-mail: massimo.brignone@unige.it; renato.procopio@unige.it).

D. Mestriner is with the DITEN, Genoa University, Genova 16145, Italy (e-mail: daniele.mestriner@edu.unige.it).

M. Rossi is with the Naval \& Electrical Engineering Department, University of Genoa, Genova 16145, Italy (e-mail: mansueto.rossi@unige.it).

A. Piantini is with the Institute of Energy and Environment (IEE/USP), University of Sao Paulo, Sao Paulo 05508-010, Brazil (e-mail: piantini@ iee.usp.br).

F. Rachidi is with the EMC Laboratory, Swiss Federal Institute of Technology, Lausanne CH-1015, Switzerland (e-mail: farhad.rachidi@epfl.ch).

Digital Object Identifier 10.1109/TEMC.2019.2911995 lightning strikes the ground or adjacent structures nearby the line.

Literature is rich of methods for evaluating overvoltages due to direct and indirect lightning events (see, e.g., [3]-[5]). Among them, the most commonly used model in lightning electromagnetic field coupling has been proposed by Agrawal et al. [6].

From [6] onward, many studies have utilized this formulation in order to evaluate lightning-induced overvoltages, such as the ones presented in [7]-[12], where analytical methods, based on an approach consisting of the evaluations of lightning-induced overvoltages into a mixed time-domain/frequency domain systems, are described. Other methods based on numerical solutions are proposed in [9], [13], and [14]. Among them it is worth citing LIOV (see e.g., [15]-[18]), which has been extensively validated using experimental data (e.g., [19] and [20]).

Recently, an advanced coupling code that can be interfaced with the PSCAD-EMTDC platform has been developed [21], [22]. Its main advantages are the possibility of connecting the coupled network to any lumped circuit present in PSCAD library, the automatic distinction between direct and indirect strikes, and the possibility to account for the power network pre-contingency conditions in an accurate way. The code has been validated in [21] comparing its results with analytical solutions available for very simple configurations and with the published results provided by LIOV. Moreover, as its implementation (detailed in [21]) allows to reduce the computational effort necessary to compute the overvoltages caused in a power system by a lightning strike, it has been used to evaluate in an accurate and fast way the lightning performance of a typical distribution system (see [23] and [24] for details).

However, an extensive validation of the code performances in different and complex configurations by means of a comparison with experimental data was still missing.

So, this paper presents a thorough comparative analysis between the code results and experimental measurements obtained, thanks to the reduced-scale model test facility built at the University of São Paulo, Brazil [19].

As will be detailed later on in the paper, the experimental setup simulates the lightning channel with a copper conductor wounded on an insulating rod to control the propagation velocity of the current along the channel model. This means that the electromagnetic field source is a helical antenna that is, in principle, different from the classical modeling of the return stroke channel consisting of a straight vertical antenna. For this reason, before proceeding with the code validation, the 
evaluation of the electromagnetic fields generated by a current propagating along a helix antenna is presented and conditions under which such fields can be approximated with the ones generated by a vertical straight wire are derived. Note that no measurements are available on the current distribution along the channel (only the channel-base current was recorded), and only the mean value of the propagation speed was evaluated [19]. The comparison between measured overvoltages and simulations is used here to infer height-dependent attenuation functions for the current and the velocity, an information that was not possible to obtain from the measurements.

The rest of the paper is organized as follows: Section II briefly recalls the main features of the experimental setup [19], while in Section III, expressions for the electromagnetic fields generated by a helical antenna are derived and the equivalence with the fields produced by a vertical antenna is discussed. Section IV presents all the test configurations and the results of the comparative analysis, followed by conclusive remarks reported in Section V. The Appendix presents a physical justification for the proposed height dependence of the current propagation speed along the radiating channel.

\section{EXPERIMENTAL SET UP}

The reduced-scale model test facility adopted for the code validation is thoroughly described in [19]. Here, the main features are briefly recalled. The scale factor is 1:50 for length and time, while 1:360 was chosen for the electromagnetic fields. This way, the scale factors of all the other quantities are uniquely determined [19].

The return stroke channel was simulated by means of a copper conductor wounded on an insulating rod in such a way that the propagation velocity of the current along the channel model was about $11 \%$ of that of light in free space. Moreover, in [19], it was assumed that the current propagates along the channel with no attenuation. The diameters of the insulating rod and of the copper conductor were $25.4 \mathrm{~mm}$ and $0.7 \mathrm{~mm}$, respectively, with approximately 323 turns per meter. The length of the stroke channel model was $12 \mathrm{~m}$.

The surge impedance of the channel model $\left(Z_{0}\right)$ and the (mean) propagation velocity along it were estimated experimentally by the analysis of reflected voltages resulting from the application of a step signal at one end, leaving the other one open. The value obtained for $Z_{0}$ was $2.2 \mathrm{k} \Omega$, and thus, in order to avoid reflections, a non-inductive resistor of the same value was connected between the top of the channel model and the mesh of conductors that provided the return path for the current. The return conductors were separated by a distance of about $1 \mathrm{~m}$ and, therefore, for the relevant frequencies of the current spectrum, they could reasonably be assumed to represent a conducting surface surrounding the system, so that the electromagnetic field in the region under analysis was established by the current injected into the model.

The ground was simulated by interconnected aluminum plates covering an area of approximately $28 \times 9 \mathrm{~m}^{2}$. The generation and measuring systems were placed below the ground plane. Additional information about the scale system, including details of the line, transformers, and surge arresters models, as well as the derivation of the scale factors corresponding to the various quantities, can be found in [19].

A schematic diagram and a general view of the experimental set up are presented in Figs. 1 and 2, respectively.

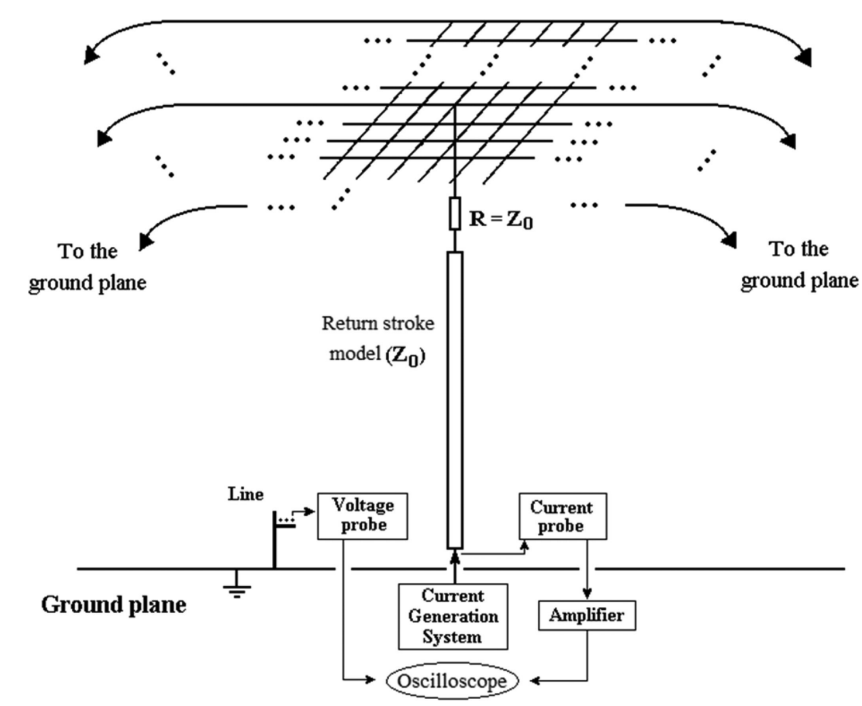

Fig. 1. Schematic diagram of the experimental set up (adapted from [19]).

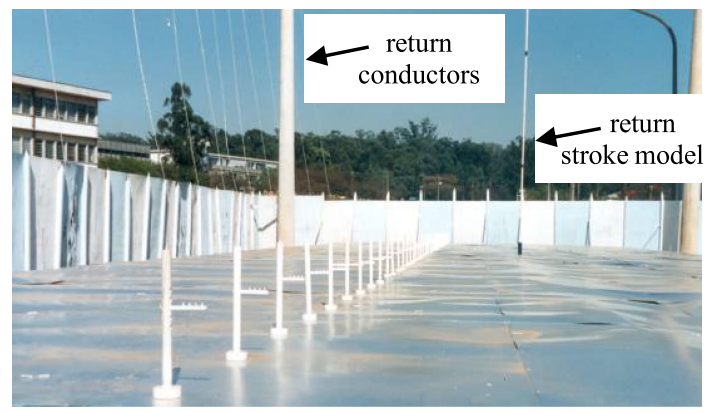

Fig. 2. General view of the scale system. Adapted from [25].

\section{Electromagnetic Fields Generated By A HELIX ANTENNA}

The problem of the electromagnetic fields generated by a helical antenna has been faced among others in [26]. However, to the best of the authors' knowledge, the problem of the propagation of the current along the antenna has never been considered. For this reason, in this section, the electromagnetic fields generated by a current propagating along a helical antenna are calculated.

As well known, in the frequency domain and assuming for all variables time harmonic dependence of the kind $e^{j \omega t}$, the electromagnetic fields produced by a current $I$ can be calculated first evaluating the vector potential $\mathbf{A}$ as the solution of

$$
\Delta \dot{\mathbf{A}}+k^{2} \dot{\mathbf{A}}=-\mu_{0} \dot{\mathbf{I}}
$$

where $k$ is the wavenumber. For a current flowing along a curve $\gamma$, one has [26]

$$
\dot{\mathbf{A}}=\frac{\mu_{0}}{4 \pi} \int_{\gamma} h\left(P^{\prime}\right) \dot{\mathbf{I}}\left(P^{\prime}\right) d \ell
$$

with

$$
h\left(P^{\prime}\right)=\frac{e^{j k \sqrt{r^{2}+r^{\prime 2}-2 r r^{\prime} \cos \left(\phi-\phi^{\prime}\right)+\left(z-z^{\prime}\right)^{2}}}}{\sqrt{r^{2}+r^{\prime 2}-2 r r^{\prime} \cos \left(\phi-\phi^{\prime}\right)+\left(z-z^{\prime}\right)^{2}}}
$$

where the generic source point $P^{\prime}=\left(r^{\prime}, \phi^{\prime}, z^{\prime}\right)$ belongs to $\gamma$ and the measurement point is $Q=(r, \phi, z)$.

In the present analysis, for sake of comparison, we will assume a current distribution along the helical antenna, which is 
similar to that used in [19]

$i\left(P^{\prime}, t\right)=i\left(0, t-\frac{L_{\gamma}\left(0, P^{\prime}\right)}{v_{h}}\right) \cdot u\left(t-\frac{L_{\gamma}\left(0, P^{\prime}\right)}{v_{h}}\right) \cdot F\left(P^{\prime}\right)$

where $v_{h}$ is the propagation speed (eventually dependent on $\mathrm{P}^{\prime}$ ), $L_{\gamma}\left(0, P^{\prime}\right)$ is the arc length on $\gamma$ between the channel base and $P^{\prime}, i(0, t)$ is the time-domain waveform of the channel base current, $F$ is the attenuation function, and $u(t)$ is the Heaviside's unit step function. So, after some straightforward mathematical manipulations, in the frequency domain, one has

$$
\dot{\mathbf{I}}=\dot{I}(0, \omega) F\left(P^{\prime}\right) \exp \left(j \omega \frac{L_{\gamma}\left(0, P^{\prime}\right)}{v_{h}}\right) \mathbf{e}_{t, P^{\prime}}
$$

$\mathbf{e}_{t, P^{\prime}}$ being the unitary tangent vector at $\gamma$ in $P^{\prime}$.

The geometry described in Section II can be modeled according to the method of images with two helical antennas $\left(\gamma_{+}\right.$and $\gamma_{-}$), whose parameterization is as follows: $\gamma=\gamma_{+} \cup \gamma_{-}$with parameter $s \in[0, H]$ and

$$
\gamma_{+}:\left\{\begin{array}{l}
x=a \cos \left(\frac{2 \pi}{p} s\right) \\
y=a \sin \left(\frac{2 \pi}{p} s\right) \gamma_{-}:\left\{\begin{array}{l}
x=a \cos \left(\frac{2 \pi}{p} s\right) \\
z=s
\end{array}=a \sin \left(\frac{2 \pi}{p} s\right)\right. \\
z=-s
\end{array}\right.
$$

where $a$ is the helix radius, $p=H / N, H$ is the channel height, and $N$ the number of turns. According to (6), one has

$$
L_{\gamma}\left(0, P^{\prime}\right)=\int_{s=0}^{z^{\prime}}\|\dot{\gamma}(s)\| d s=z^{\prime} L
$$

being for the sake of simplicity

$$
L=\sqrt{\left(\frac{2 \pi a}{p}\right)^{2}+1} .
$$

Moreover if $P^{\prime} \in \gamma_{+}$, then

$$
\mathbf{e}_{t, P^{\prime}}=\frac{1}{L}\left(\frac{2 \pi a}{p} \mathbf{e}_{\phi^{\prime}}+\mathbf{e}_{z}\right)
$$

while when $P^{\prime} \in \gamma_{-}$

$$
\mathbf{e}_{t, P^{\prime}}=\frac{1}{L}\left(\frac{2 \pi a}{p} \mathbf{e}_{\phi^{\prime}}-\mathbf{e}_{z}\right) .
$$

$\mathbf{e}_{\phi^{\prime}}\left(\mathbf{e}_{z}\right)$ being the azimuthal (vertical) unitary vector in point $\mathrm{P}^{\prime}$. Inserting (9) and (10) into (5), (5) into (2), and exploiting the well-known relationships between vector potential and electromagnetic fields [26], one has

$$
\begin{aligned}
E_{r}= & \frac{\mathrm{j}}{4 \pi \varepsilon_{0} \omega} \int_{\gamma}\left[\dot{I}_{\phi} \cos \left(\phi-\phi^{\prime}\right)\left[\frac{1}{r} h_{r \phi}-\frac{1}{r^{2}} h_{\phi}\right]\right. \\
& \left.+\dot{I}_{\phi} \sin \left(\phi-\phi^{\prime}\right)\left[h_{r r}+k^{2} h\right]+\dot{I}_{z} h_{r z}\right] d \ell
\end{aligned}
$$

$$
\begin{aligned}
E_{\phi}= & \frac{j}{4 \pi \varepsilon_{0} \omega} \int_{\gamma}\left[\dot{I}_{\phi} \sin \left(\phi-\phi^{\prime}\right)\left(\frac{1}{r} h_{\phi r}-\frac{1}{r^{2}} h_{\phi}\right)\right. \\
& +\dot{I}_{\phi} \cos \left(\phi-\phi^{\prime}\right)\left(\frac{1}{r^{2}} h_{\phi \phi}+\frac{1}{r} h_{r}+k^{2} h\right) \\
& \left.+\dot{I}_{z}\left(\frac{1}{r} h_{\phi z}\right)\right] d \ell \\
E_{z}= & \frac{\mathrm{j}}{4 \pi \varepsilon_{0} \omega} \int_{\gamma}\left[\frac{1}{r} h_{z \phi} \dot{I}_{\phi} \cos \left(\phi-\phi^{\prime}\right)\right. \\
& \left.+\frac{\partial^{2} h}{\partial z \partial r} \dot{I}_{\phi} \sin \left(\phi-\phi^{\prime}\right)+\left(h_{z z}+k^{2} h\right) \dot{I}_{z}\right] d \ell
\end{aligned}
$$

having indicated with subscript $x$ the partial derivative of the function with respect to variable $x$. In all the above-mentioned expressions

$$
\dot{I}_{\phi}=\frac{2 \pi a}{L p} \dot{I}\left(P^{\prime}, \omega\right)
$$

and

$$
\dot{I}_{z}=\left\{\begin{array}{ll}
\frac{1}{L} \dot{I}\left(P^{\prime}, \omega\right) & \text { if } P^{\prime} \in \gamma_{+} \\
-\frac{1}{L} \dot{I}\left(P^{\prime}, \omega\right) & \text { if } P^{\prime} \in \gamma_{-}
\end{array} .\right.
$$

Assuming that $r \gg r^{\prime}=a, r^{\prime}$ can be considered null in (3) so that the expression of $h$ can be approximated as

$$
h\left(P^{\prime}\right) \approx \tilde{h}\left(P^{\prime}\right)=\frac{e^{j k \sqrt{r^{2}+\left(z-z^{\prime}\right)^{2}}}}{\sqrt{r^{2}+\left(z-z^{\prime}\right)^{2}}} .
$$

Hence, (11)-(13) become

$$
\begin{aligned}
& E_{r}=\frac{\mathrm{j}}{4 \pi \varepsilon_{0} \omega} \int_{\gamma}\left[\dot{I}_{\phi} \sin \left(\phi-\phi^{\prime}\right)\left[\tilde{h}_{r r}+k^{2} \tilde{h}\right]+\dot{I}_{z} \tilde{h}_{r z}\right] d \ell \\
& E_{\phi}=\frac{\mathrm{j}}{4 \pi \varepsilon_{0} \omega} \int_{\gamma}\left[\dot{I}_{\phi} \cos \left(\phi-\phi^{\prime}\right)\left[\frac{1}{r} \tilde{h}_{r}+k^{2} \tilde{h}\right]\right] d \ell \\
& E_{z}=\frac{\mathrm{j}}{4 \pi \varepsilon_{0} \omega} \int_{\gamma}\left[\dot{I}_{\phi} \sin \left(\phi-\phi^{\prime}\right) \tilde{h}_{r z}+\dot{I}_{z}\left[\tilde{h}_{z z}+k^{2} \tilde{h}\right]\right] d \ell .
\end{aligned}
$$

It is easy to show that if

$$
\left.\dot{I}\left(P^{\prime}, \omega\right)\right|_{P^{\prime} \in \gamma_{+}}+\left.\dot{I}\left(P^{\prime}, \omega\right)\right|_{P^{\prime} \in \gamma_{-}}=0
$$

both the radial and the azimuthal components of the electric field are zero at the ground level, which means that, according to (6), the image antenna has to carry the same current as the source one.

Hence, (17)-(19) become

$$
\begin{aligned}
E_{r}= & \frac{j}{4 \pi \varepsilon_{0} \omega} \int_{s=0}^{H} \dot{I}(s, \omega)\left\{\left[\left(\tilde{h}_{r z}\right)_{\mid z^{\prime}=s}+\left(\tilde{h}_{r z}\right)_{\mid z^{\prime}=-s}\right]\right. \\
& +\frac{2 \pi a}{p} \sin \left(\phi-\frac{2 \pi s}{p}\right)\left[\left(\tilde{h}_{r r}+k^{2} \tilde{h}\right)_{\mid z^{\prime}=s}+\right. \\
& \left.\left.-\left(\tilde{h}_{r r}+k^{2} \tilde{h}\right)_{\mid z^{\prime}=-s}\right]\right\} d s
\end{aligned}
$$



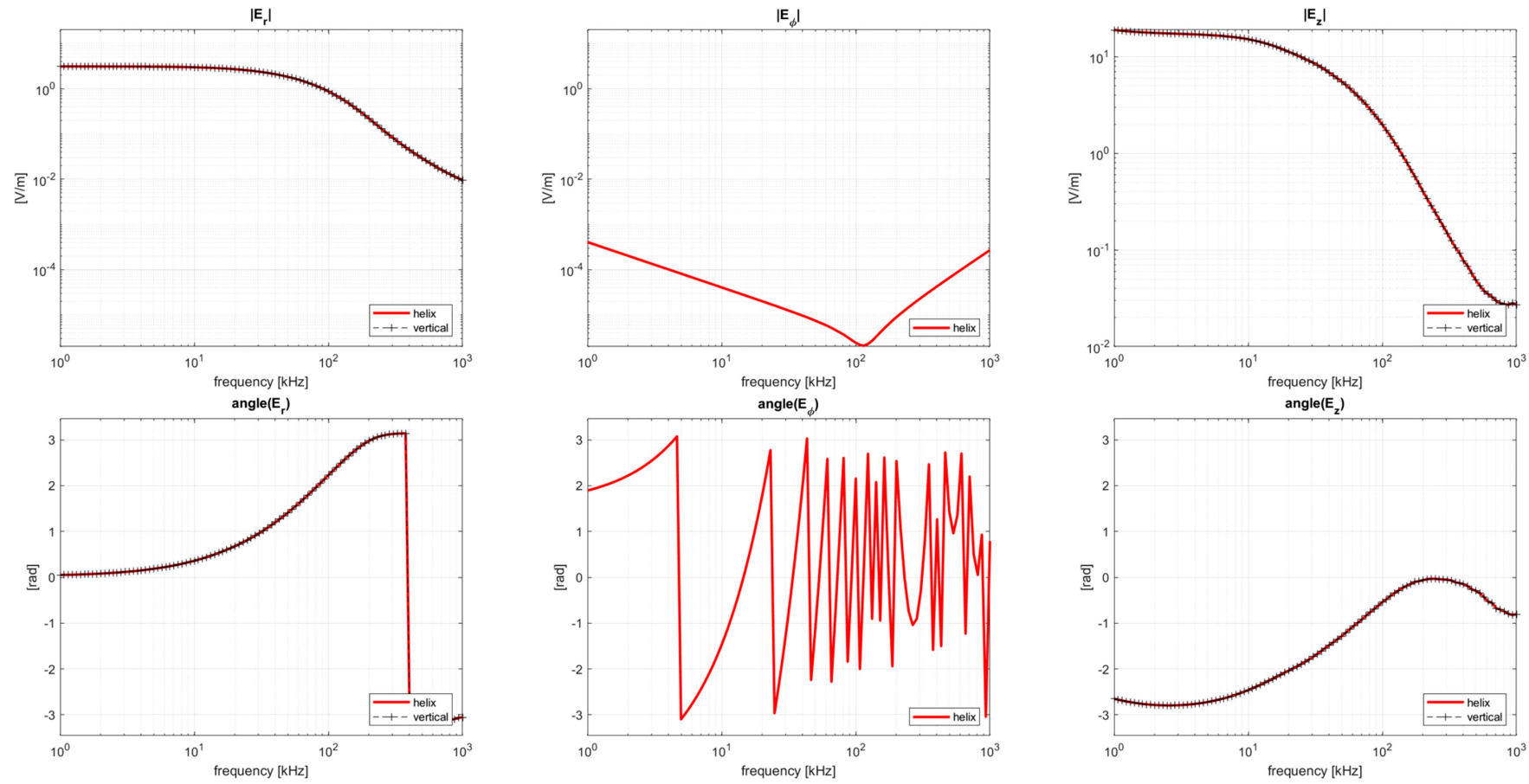

Fig. 3. Radial, azimuthal, and vertical electric field magnitude and phase spectra for vertical and helix antenna at $(x, y, z)=(0,70,10)$.

$$
\begin{aligned}
E_{\phi}= & \frac{j}{4 \pi \varepsilon_{0} \omega} \int_{s=0}^{H}\left\{\frac{2 \pi a}{p} \dot{I}(s, \omega) \cos \left(\phi-\frac{2 \pi s}{p}\right) \cdot\right. \\
\cdot & {\left[\left(\frac{1}{r} \tilde{h}_{r}+k^{2} \tilde{h}\right)_{\mid z^{\prime}=s}-\left(\frac{1}{r} \tilde{h}_{r}+k^{2} \tilde{h}\right)_{\mid z^{\prime}=-s}\right] d s } \\
E_{z}= & \frac{j}{4 \pi \varepsilon_{0} \omega} \int_{s=0}^{H} \dot{I}(s, \omega)\left\{\frac{2 \pi a}{p} \sin \left(\phi-\frac{2 \pi s}{p}\right)\right. \\
& \cdot\left[\left(\tilde{h}_{r z}\right)_{\mid z^{\prime}=s}-\left(\tilde{h}_{r z}\right)_{\mid z^{\prime}=-s}\right] \\
& \left.+\left[\left(\tilde{h}_{z z}+k^{2} \tilde{h}\right)_{\mid z^{\prime}=s}+\left(\tilde{h}_{z z}+k^{2} \tilde{h}\right)_{\mid z^{\prime}=-s}\right]\right\} d s
\end{aligned}
$$

having highlighted the dependence of the current on the two curves parameter $s$.

Expressions (21)-(23) represent the electromagnetic fields generated by a current flowing into a helical antenna over a perfectly conducting ground.

It is easy to understand that, setting $a=0$ and $v=v_{h} L^{-1}=$ $v_{h}\left[\left(\frac{2 \pi a}{p}\right)^{2}+1\right]^{-1 / 2}(v$ being the propagation speed along the vertical channel), one gets the expressions for the electric field produced by the classical lightning channel model [2].

In Figs. 3 and 4, the magnitude and the phase spectra of the three components of the electric field are plotted in order to compare the fields generated by the helix [exact formulas (21)-(23), with $a=63.5 \mathrm{~cm}$, namely the radius in the full-scale model] with those produced by the vertical antenna [formulas (21)-(23) with $a=0]$. The fields are plotted at $z=10 \mathrm{~m}$, in points $(0,70)$ (see Fig. 3) and $(350,70)$ (see Fig. 4) assuming that the lightning strikes in point $(0,0)$. Moreover, $\dot{I}(0, \omega)=1$ is assumed for calculations. The exam of the figures suggests that it is possible to approximate the helix with a straight vertical antenna. Please note that the azimuthal component of the electric field is identically zero in the case of a vertical channel and so it has not been plotted.

A possible explanation of the similar behavior between the fields produced by the two different antennas can be given examining again (21)-(23): if $H$ is an integer multiple of $p$, for any element taking current $I$ at point $(a, \phi, s)$, there is another element taking current $-I$ at point $(a, \phi+\pi, s+p / 2)$. If both $a$ and $p$ are small with respect to the distance between the source and observation points, these two elements produce fields that cancel with each other. From a mathematical point of view, this is confirmed by the presence of terms of the kind $\sin (\phi-2 \pi s / p)$ and $\cos (\phi-2 \pi s / p)$ to be integrated in $d s$ over a multiple of their period.

\section{COMPARISON BETWEEN CALCULATIONS AND MEASUREMENTS}

Three test cases characterized by an increasing level of complexity are presented as follows.

1) Test case A considers a very simple line topology in order to test the effective implementation of the finite difference time domain (FDTD) method that discretizes the Agrawal et al. equations and the imposition of the boundary conditions (see [27] for details).

2) Test case $B$ introduces the presence of discontinuities along the lines as well as the variation of grounding resistance values, shield wire height, and other parameters (see [28] for details).

3) Test case C, finally, validates the modeling of surge arresters with their non-linear characteristics and accounts for a much more complex network topology [19], with one main feeder and many laterals. 

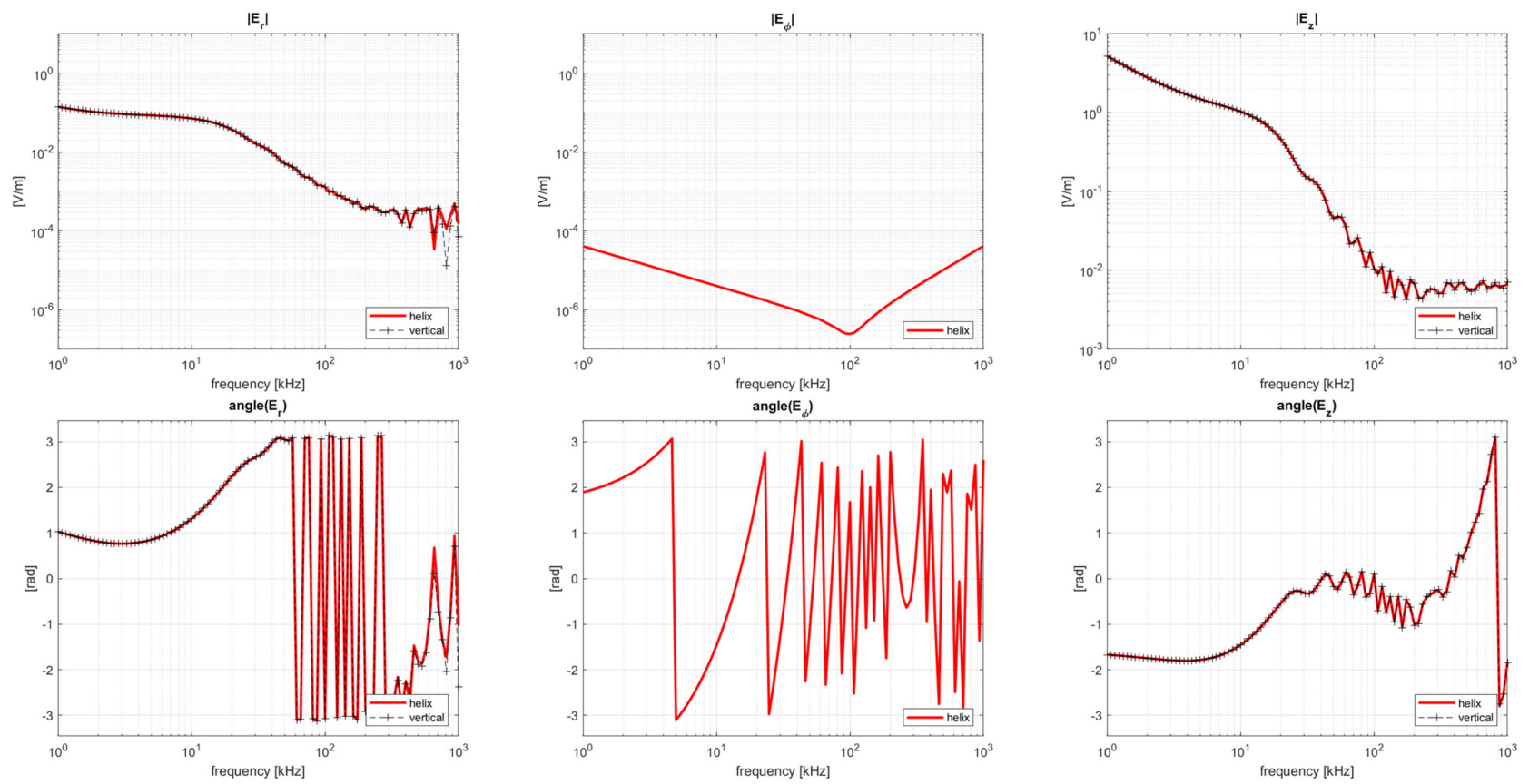

Fig. 4. Radial, azimuthal, and vertical electric field magnitude and phase spectra for vertical and helix antenna at $(x, y, z)=(350,70,10)$.

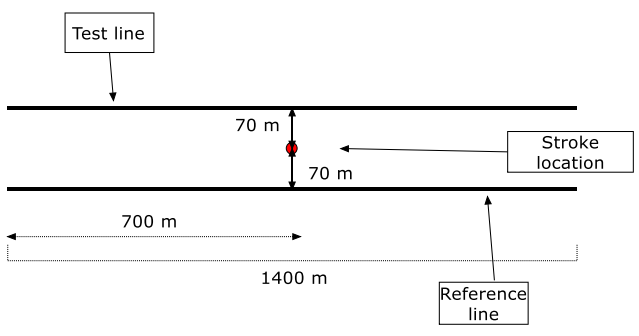

Fig. 5. Case A line configuration. Top view.

\section{A. Single-Phase Straight Distribution Line}

This section aims at validating the coupling code for the test case A, represented in Fig. 5, where the stroke location is evidenced.

Such system consists of a reference line, always matched at both ends, and a test line whose boundary conditions can vary. The test line is placed symmetrically to the reference line with respect to the lightning channel model [27].

Five different tests, each involving different values for the current peak and front time and characterized by different types of line terminations, have been considered (see Table I for details). In all the cases, the channel-base current waveform is described in the coupling code by means of a saturated ramp, whose parameters appear in columns 2 and 3 of Table I. The measured and the saturated ramp current waveforms are presented in Figs. 6 and 7 for cases A1 and A2, respectively (for cases A3, A4, and A5, the experimental waveforms for the current are not available).

First of all, calculations are performed assuming the transmission line (TL) model [29] for the return stroke and a constant propagation speed equal to $0.11 \mathrm{c}$.

Figs. 8 and 9 show, for cases A1 and A2, the time-domain waveforms of the voltages induced at the reference line center, which is the point of the reference line closest to the lightning strike point.

TABLE I

DETAILS FOR CASES A

\begin{tabular}{|c|c|c|c|c|}
\hline \multicolumn{6}{|c|}{ Cases A details } \\
\hline Case & $\begin{array}{c}\text { Current } \\
\text { Peak value }\end{array}$ & $\begin{array}{c}\text { Current } \\
\text { front } \\
\text { duration }\end{array}$ & $\begin{array}{c}\text { Test Line } \\
\text { terminations }\end{array}$ & $\begin{array}{c}\text { Reference Line } \\
\text { terminations }\end{array}$ \\
\hline A1 & $21.6 \mathrm{kA}$ & $3.1 \mu \mathrm{s}$ & $\begin{array}{c}\text { Matched at both } \\
\text { ends }\end{array}$ & $\begin{array}{c}\text { Matched at both } \\
\text { ends }\end{array}$ \\
\hline A2 & $22.8 \mathrm{kA}$ & $5.75 \mu \mathrm{s}$ & $\begin{array}{c}\text { Matched at both } \\
\text { ends }\end{array}$ & $\begin{array}{c}\text { Matched at both } \\
\text { ends }\end{array}$ \\
\hline A3 & $19.8 \mathrm{kA}$ & $3.0 \mu \mathrm{s}$ & $\begin{array}{c}\text { One end opened } \\
\text { and one matched }\end{array}$ & $\begin{array}{c}\text { Matched at both } \\
\text { ends }\end{array}$ \\
\hline A4 & $19.8 \mathrm{kA}$ & $3.0 \mu \mathrm{s}$ & $\begin{array}{c}\text { One end short } \\
\text { circuited and one } \\
\text { matched }\end{array}$ & $\begin{array}{c}\text { Matched at both } \\
\text { ends }\end{array}$ \\
\hline A5 & $19.8 \mathrm{kA}$ & $3.0 \mu \mathrm{s}$ & $\begin{array}{c}\text { One end open and } \\
\text { one short circuited }\end{array}$ & $\begin{array}{c}\text { Matched at both } \\
\text { ends }\end{array}$ \\
\hline
\end{tabular}

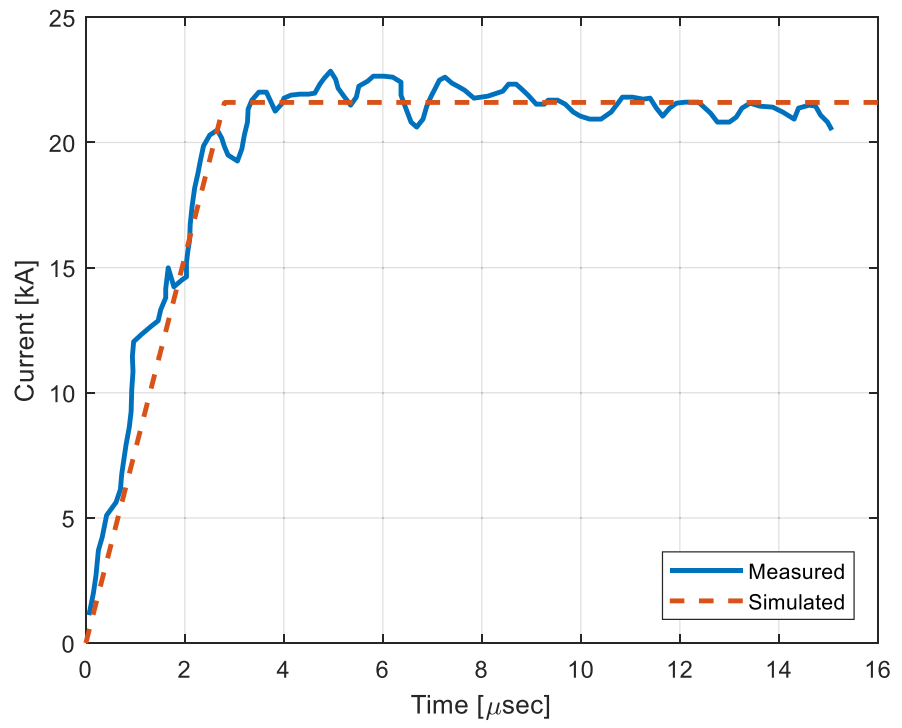

Fig. 6. Channel base current A1. 


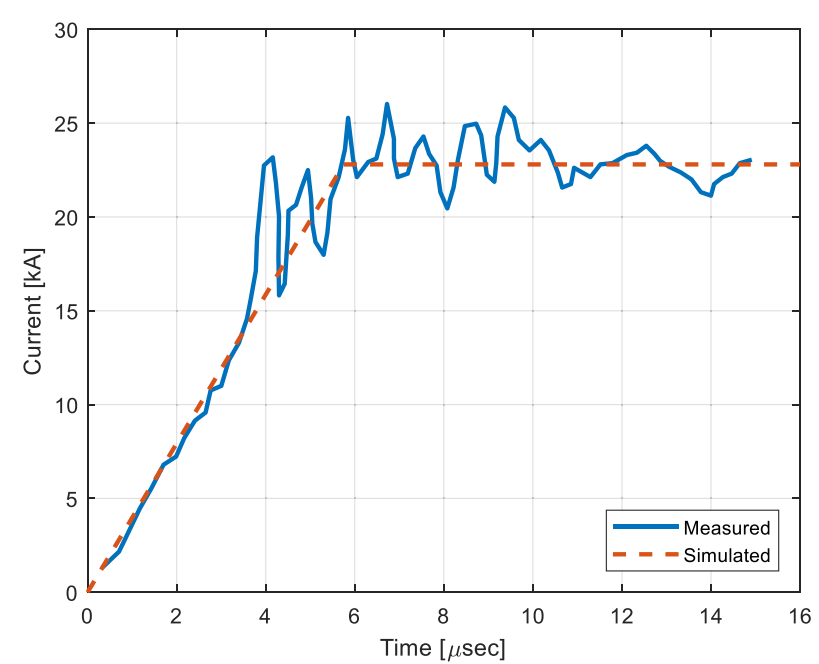

Fig. 7. Channel base current A2.

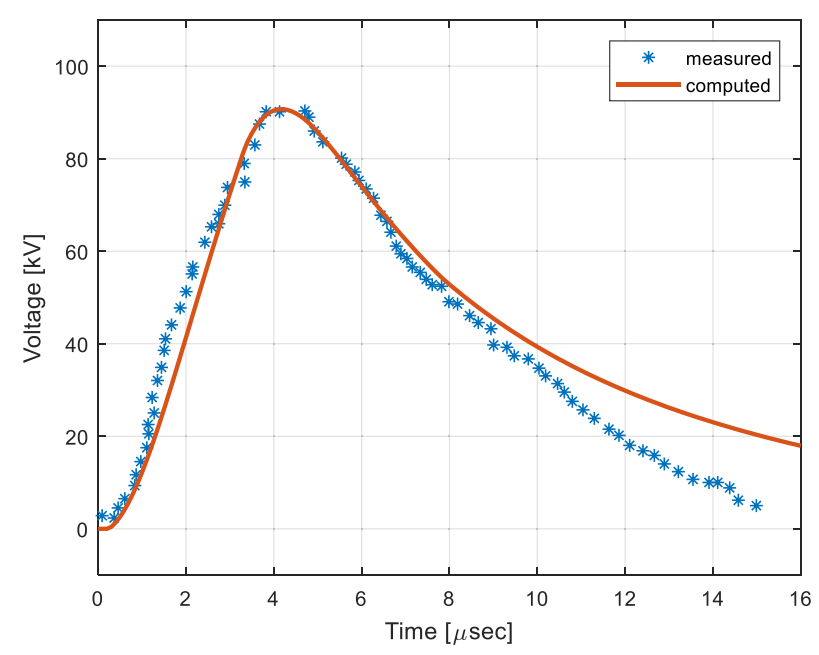

Fig. 8. Measured and calculated induced voltages (case A1).

A very good agreement can be observed, except for some deviations in the waveform tails. As it has been shown that for the calculation of the fields, the helix can be equivalently represented by a vertical antenna, two possible causes of these differences can be identified as unitary height dependent attenuation function (TL model) and the assumption of a constant speed equal to its mean value. In particular, as far as the speed is concerned, simulations and previous works [30], [31] confirmed the intuitive insight that higher speed implies a faster decay to zero of the overvoltage waveform.

The considerations provided in the Appendix show that the vertical speed of the current pulse along the helical antenna increases as a function of height, while the current peak remains quasi-constant.

For this reason, after some empirical adjustments, the following expression is proposed for the propagation speed along the channel that guarantees the best fitting between measurements and calculations:

$$
v\left(z^{\prime}\right)= \begin{cases}v_{0} & \left|z^{\prime}\right|<z_{0} \\ \frac{v_{H}-v_{0}}{H-z_{0}}\left(\left|z^{\prime}\right|-z_{0}\right)+v_{0} & \left|z^{\prime}\right| \geq z_{0}\end{cases}
$$

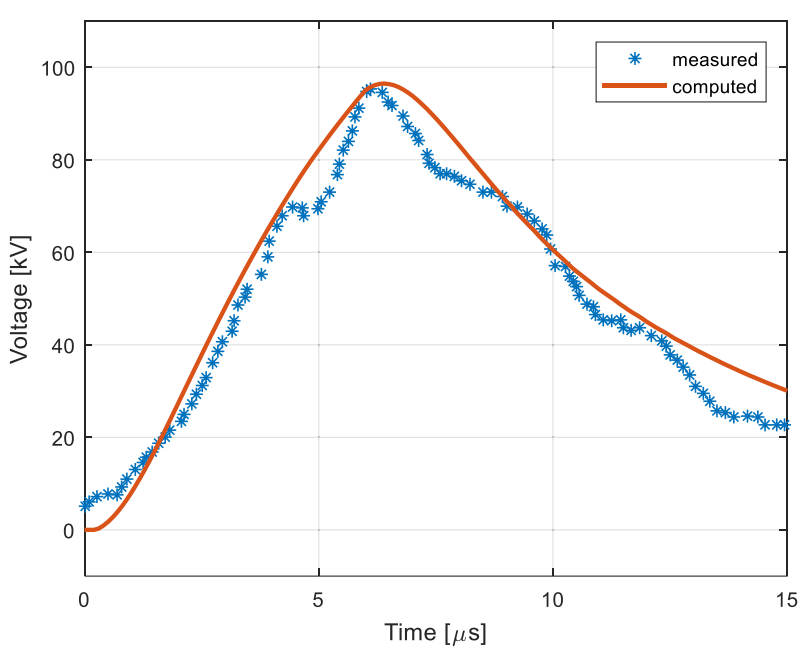

Fig. 9. Measured and calculated induced voltages (case A2).

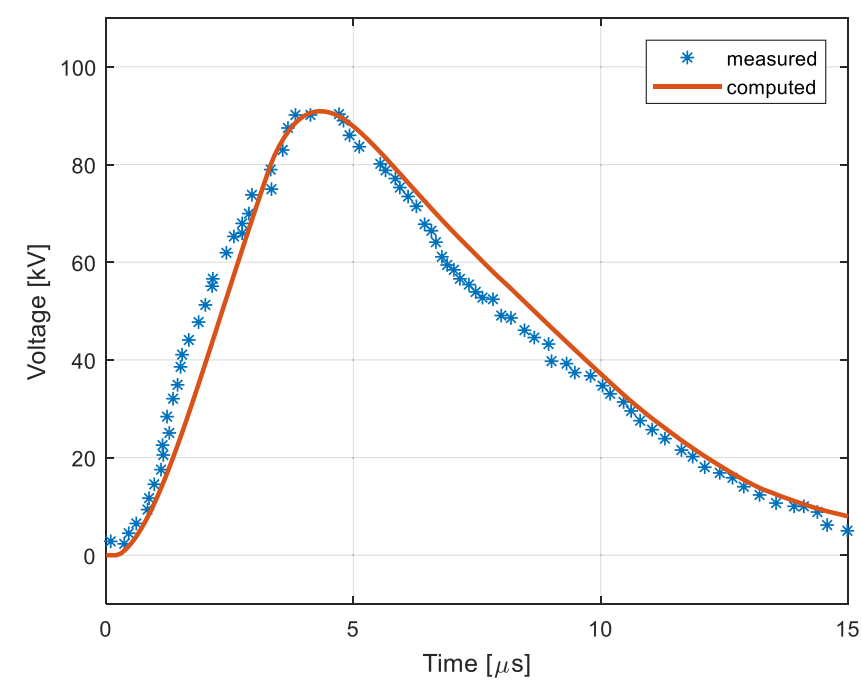

Fig. 10. Measured and calculated induced voltages (case A1).

with $v_{0}=0.3 \cdot 10^{8} \mathrm{~ms}^{-1}, \quad v_{H}=0.6 \cdot 10^{8} \mathrm{~ms}^{-1}$, and $z_{0}=$ $200 \mathrm{~m}$, whose mean value is $0.136 c$ (slightly higher than the measured value).

Henceforth, from here onward each validation case will be presented assuming (24) for the propagation speed.

In particular, in Figs. 10 and 11, cases A1-A2 are presented again and their matching with the experimental data undoubtedly improve.

The assumption proposed in (24) is applied also to cases A3A5 and the results shown in Figs. 12-14 confirm the adequacy of the proposed methodology.

Please note that in Figs. 12-14 " $R$ " and " $T$ " indicate the test line and reference line, respectively.

\section{B. Discontinuities}

The aim of this section is to validate the code for test line configurations involving discontinuities [28], due to the presence of the shield wire groundings. The line configuration is depicted in Figs. 15 and 16.

Two test setups (named B1 and B2) have been considered for validating the code, where various positions for the grounding 


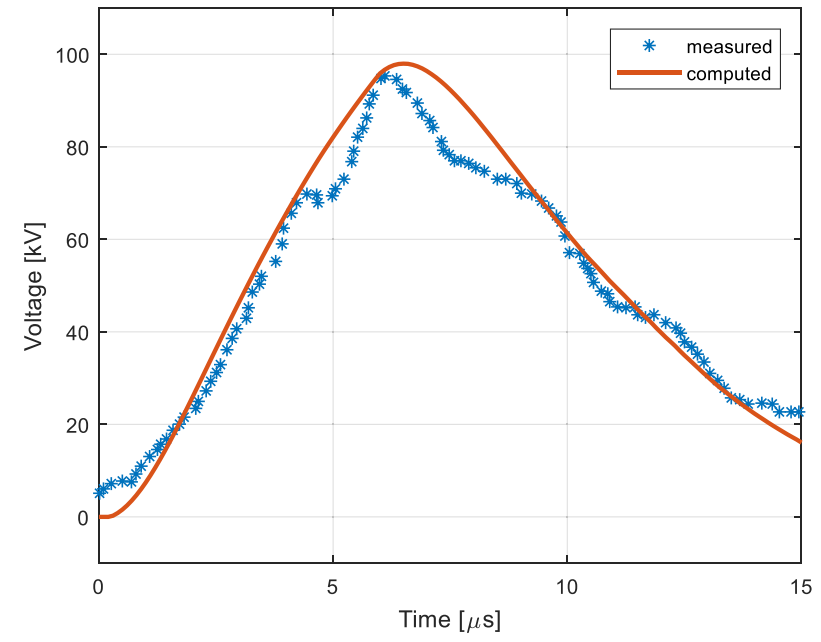

Fig. 11. Measured and calculated induced voltages (case A2).

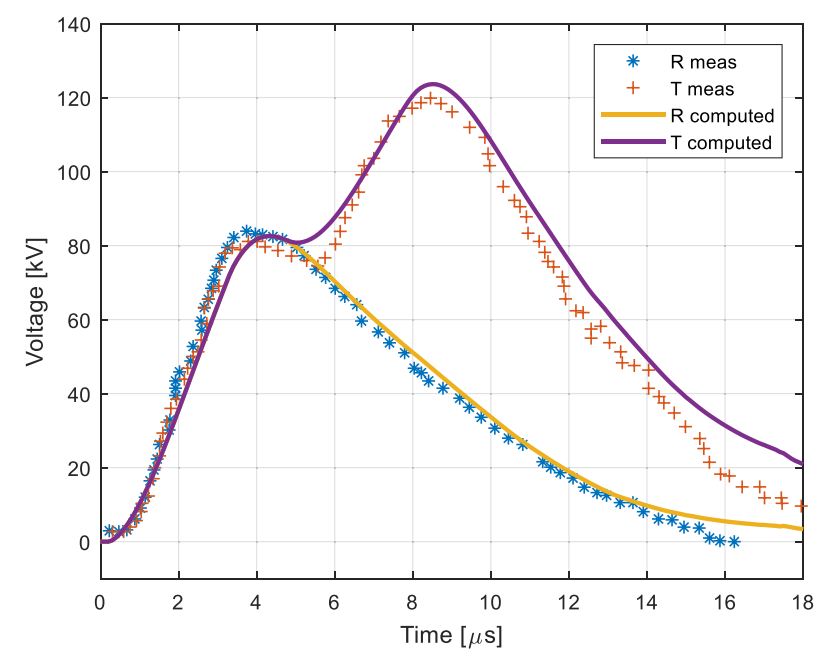

Fig. 12. Measured and calculated induced voltages (case A3).

TABLE II

DETAILS FOR CASES B

\begin{tabular}{|c|c|c|c|}
\hline \multicolumn{4}{|c|}{ Cases B details } \\
\hline Case & $h_{g}$ & $x_{g}$ & $R_{g}$ \\
\hline B1 & $7 \mathrm{~m}$ & $250,700,1150[\mathrm{~m}]$ & $0 \Omega$ \\
\hline B2 & $7 \mathrm{~m}$ & $325,1075[\mathrm{~m}]$ & $50 \Omega$ \\
\hline
\end{tabular}

points $\left(x_{g}\right)$ and different ground resistance values $\left(R_{g}\right)$ [28] have been considered (see Table II for details).

The channel-base current waveform shown in Fig. 17 needs an analytical expression to be inserted in the code. For this reason, the experimental data were fitted with a saturated ramp together with a damped sinusoidal wave, which is also shown in Fig. 17.

Figs. 18 and 19 show the comparison between measured and computed phase-to-ground induced voltages on the point closest to the stroke location for cases B1 and B2, respectively, highlighting in all the cases a very good agreement in the rising transient and in the peak estimation, as well as in the voltage tails.

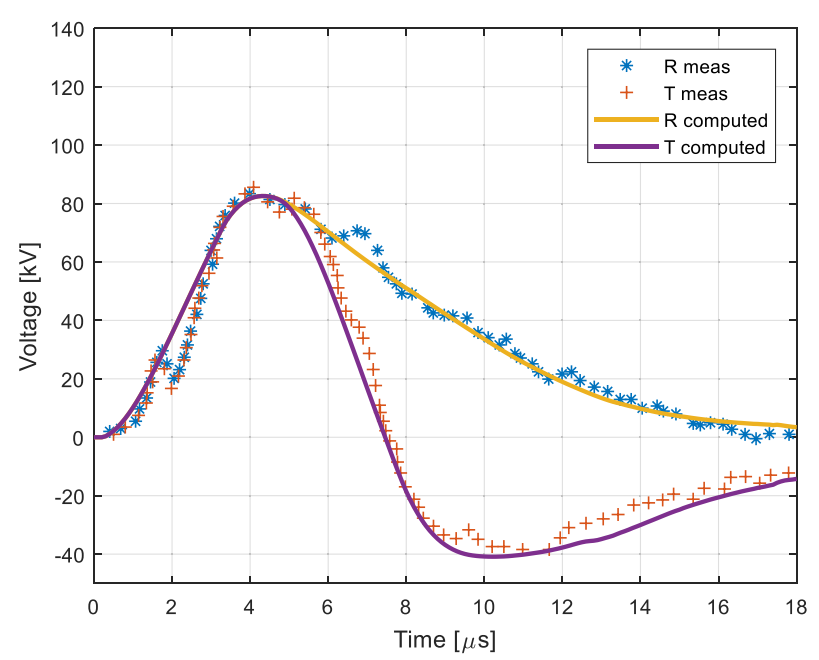

Fig. 13. Measured and calculated induced voltages (case A4).

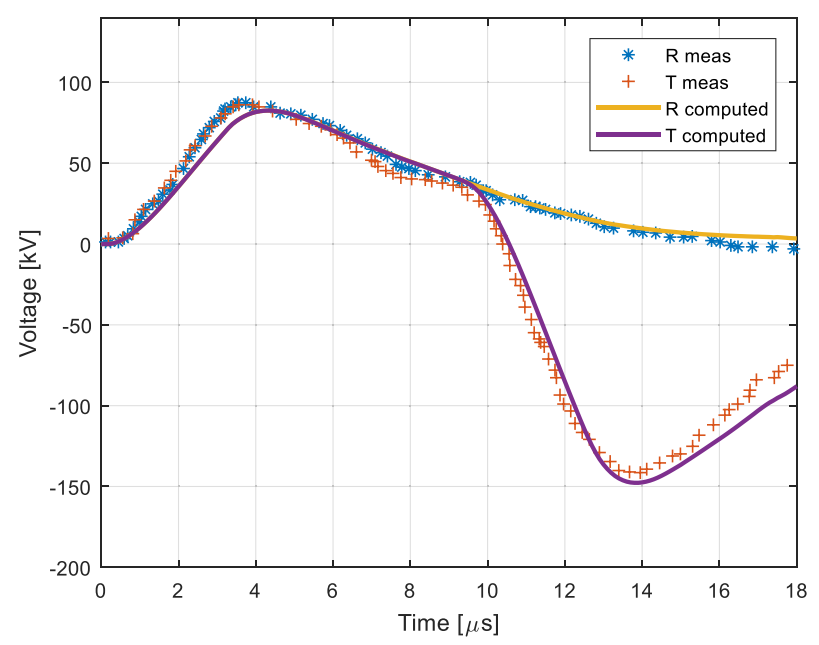

Fig. 14. Measured and calculated induced voltages (case A5).

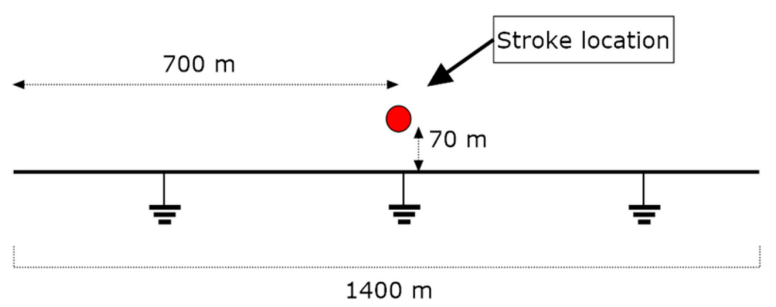

Fig. 15. Case B1 configuration.

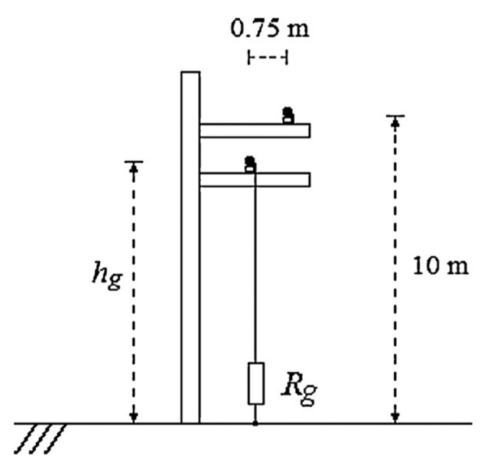

Fig. 16. Cases B frontal view [28]. 


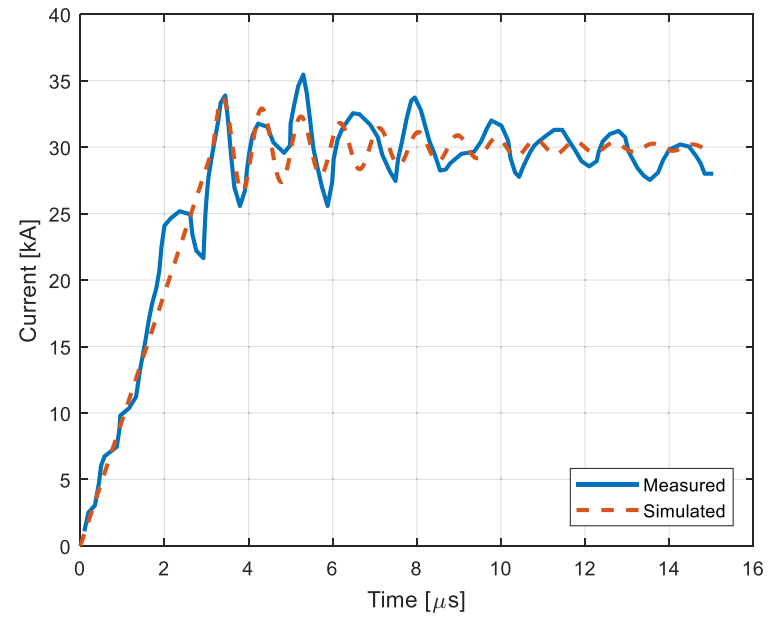

Fig. 17. Input current waveform. Continuous line: measured waveform. Dashed line: analytical representation using a saturated ramp and a damped sinusoid.

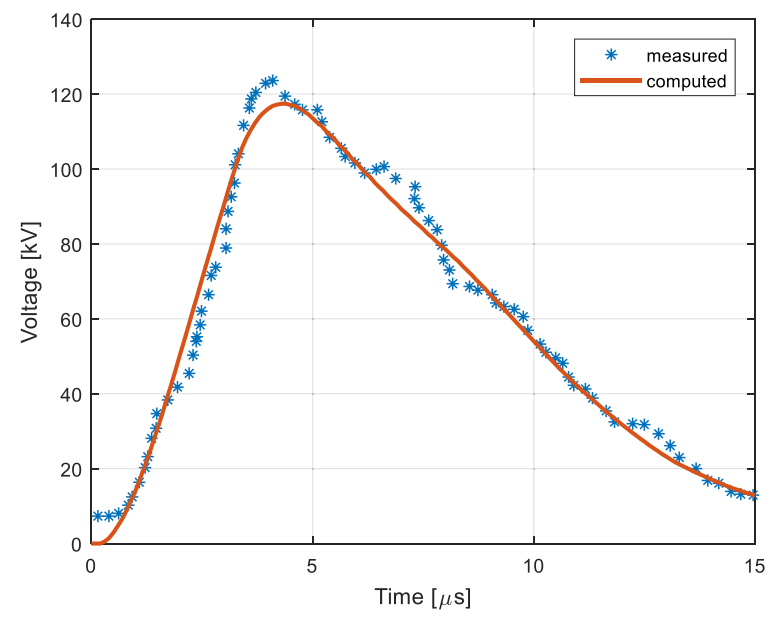

Fig. 18. Measured and calculated induced voltages—Case B1.

TABLE III

CAses C-Stroke CurRent Details

\begin{tabular}{|c|c|c|c|}
\hline \multicolumn{4}{|c|}{ Cases C-b stroke current } \\
\hline Case & Peak value & Time to peak & $\begin{array}{c}\text { Time to half } \\
\text { value }\end{array}$ \\
\hline $\mathrm{C} 1$ & $34 \mathrm{kA}$ & $2 \mu \mathrm{s}$ & $85 \mu \mathrm{s}$ \\
\hline $\mathrm{C} 2$ & $50 \mathrm{kA}$ & $2 \mu \mathrm{s}$ & $85 \mu \mathrm{s}$ \\
\hline
\end{tabular}

\section{Presence of Surge Arresters and Multi-Lateral Configuration}

In this section, all the tests were performed on a fourconductor line (three phases and neutral) with geometry shown in Fig. 20 and in Fig. 21, where r.s.m. stands for return stroke model, each triangle represents a medium voltage/low voltage transformer, and each circle represents a set of surge arresters (one per phase, see [19] for details).

Two cases are presented, whose details in terms of stroke current waveform (assumed to be triangular) are described in Table III. The measurement point is situated at node M2 (see Fig. 21).

The first case, $\mathrm{C} 1$, is characterized by the topology presented in Fig. 21, where the surge arresters are placed in parallel with the transformer at the measuring node M2. In the configuration

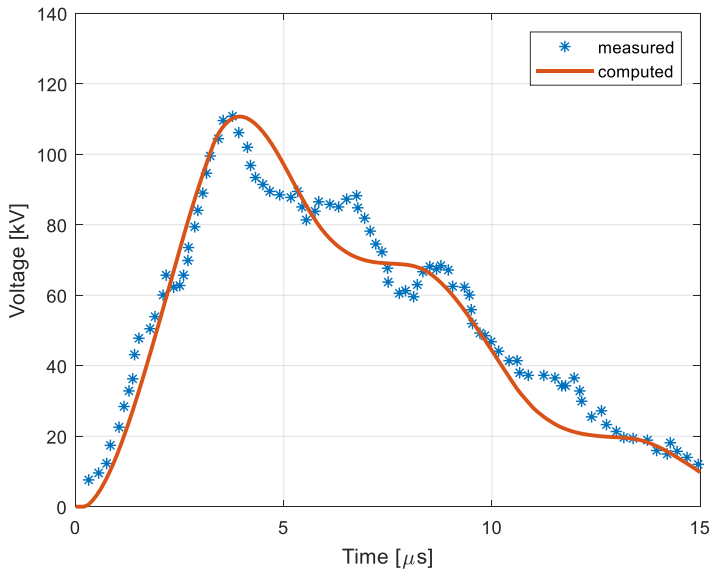

Fig. 19. Measured and calculated induced voltages — Case B2.

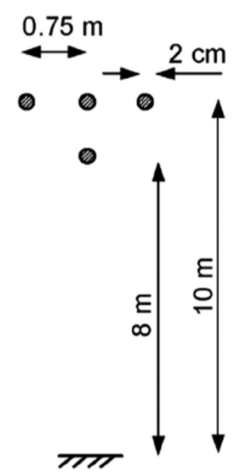

Fig. 20. Considered line geometry for cases C.

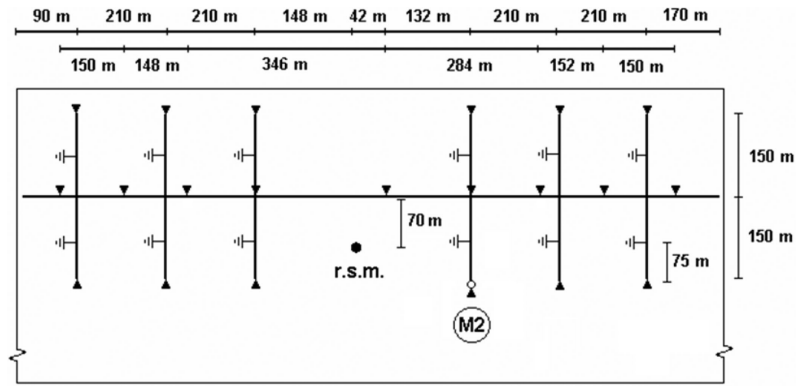

Fig. 21. Network configuration C1. Neutral conductor grounded at all transformers, surge arresters, and in the middle of all laterals. Arrester located at point M2.

$\mathrm{C} 2$, the surge arresters were moved from that point and placed in parallel with the transformer at $150 \mathrm{~m}$ from M2.

Figs. 22 and 23 present the induced voltages at the measurement point in the two cases previously described and highlight a good agreement between the two approaches.

The observed discrepancies could be attributed to several reasons. From the calculation standpoint, it should be observed that, for computational reasons, all the lengths of the involved lines and the positions of all the discontinuities have to be in correspondence with the sampling points of the FDTD method. In these simulations, the distance between two subsequent sampling points is $10 \mathrm{~m}$, which means that, for example, the length of the main feeder has been approximated to $1420 \mathrm{~m}$, rather than $1422 \mathrm{~m}$, and the discontinuities occurring on the laterals have been moved to 70 and $230 \mathrm{~m}$, rather than $75 \mathrm{~m}$ and $225 \mathrm{~m}$. 


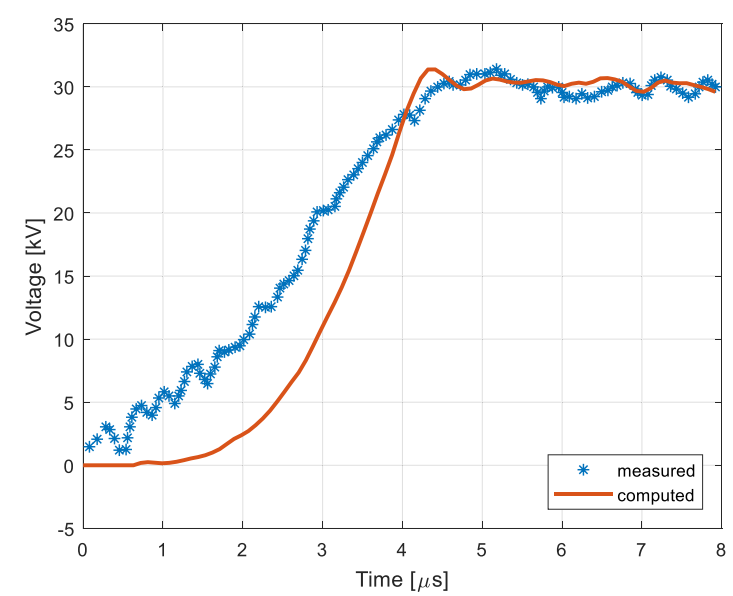

Fig. 22. Measured and calculated induced voltages (case C1).

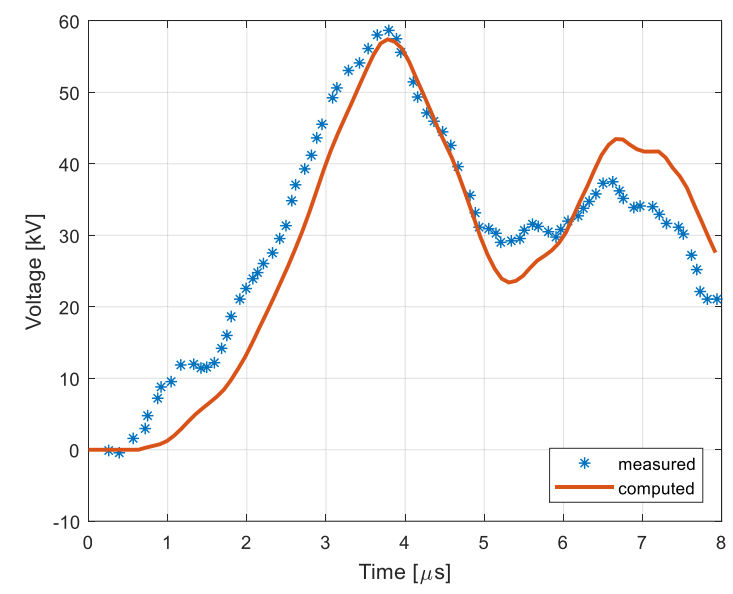

Fig. 23. Measured and calculated induced voltages (case C2).

Moreover, the implementation of the Agrawal et al. model used in the coupling code follows its main hypothesis that assumes that all the multi-conductor transmission lines are parallel. This way, the main feeder and each lateral have to be considered as uncoupled systems. In other words, the mutual coupling between the feeder and the laterals was neglected.

From the reduced scale system aspect, as pointed out in [19], possible reasons for such discrepancies are as follows.

1) Measuring errors: the overall uncertainty of the measuring system used in the tests was less than 5\%.

2) Slight deviations of the stroke current from the waveforms considered in the calculations.

3) High-frequency oscillations associated with noise or switching of the current generation system (both of random nature).

4) Imperfect representation of the current and speed distribution along the lightning channel model.

\section{CONCLUSION}

The paper presented the results of some comparisons between the simulations performed with a coupling code implemented in the PSCAD-EMTDC environment and measurements carried out in a reduced-scale model, highlighting a very good agreement in the evaluation of the overvoltages induced by a lightning strike on a distribution system. The comparisons show good performances of the coupling code both in simple cases, such as a straight feeder, and in more complex topologies, including the presence of discontinuities, nonlinear elements such as surge arresters and line laterals.

Moreover, the fact that the reduced scale model emulates the return stroke channel with an helical antenna has allowed to derive suitable expressions for the resulting electromagnetic fields and conditions under which they can be approximated with the ones produced by a vertical one. Moreover, the analysis of the deviations between measurements and calculations allowed to get useful information on the individual effect on the resulting overvoltages of, first, the propagation speed of the current along the helix and, second, its height dependent attenuation function, and to select the best representation for them to obtain the best fitting.

\section{APPENDIX}

In order to physically justify the assumption of a propagation speed increasing with height and a unitary height dependent attenuation function, the experimental setup described in Section II has been simulated using the Numerical Electromagnetics Code (NEC-2) [32], which is based on the method of moments in the frequency domain.

The simulations were setup as follows. For a given frequency, a voltage source equal to $1+\mathrm{j} 0 \mathrm{~V}$ is placed on the first segment of the helix (i.e., at $\left.z^{\prime}=0\right)$ and then the current $I\left(z^{\prime}, \omega\right)$ along the antenna is monitored.

Recalling (5) one has

$$
I\left(z^{\prime}, \omega\right)=I(0, \omega) P\left(z^{\prime}\right) \exp \left(j \omega \frac{z^{\prime}}{v}\right) .
$$

Dividing the current at height $z^{\prime}$ by the one of the first segment yields

$$
K\left(z^{\prime}, \omega\right)=\frac{I\left(z^{\prime}, \omega\right)}{I(0, \omega)}=P\left(z^{\prime}\right) \exp \left(j \omega \frac{z^{\prime}}{v}\right) .
$$

The amplitude of $K$, as a result of NEC-2 simulations, gives information on the attenuation function, while its phase angle allows to evaluate the dependence of the speed in the vertical direction as

$$
\begin{aligned}
P\left(z^{\prime}\right) & =\left|K\left(z^{\prime}, \omega\right)\right| \\
v & =\frac{z^{\prime}}{\omega} \text { angle }\left(K\left(z^{\prime}, \omega\right)\right) .
\end{aligned}
$$

Figs. 24 and 25 show the behavior of the attenuation function $P\left(z^{\prime}\right)$ and the propagation speed as a function of the height for

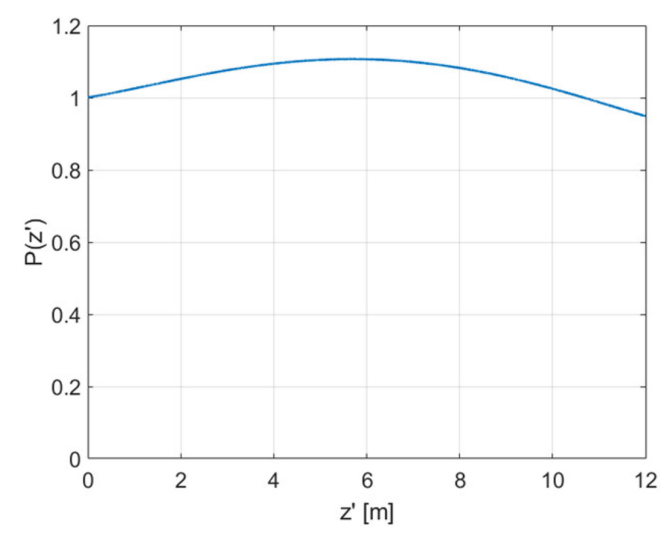

Fig. 24. Attenuation function $P\left(z^{\prime}\right)$. 


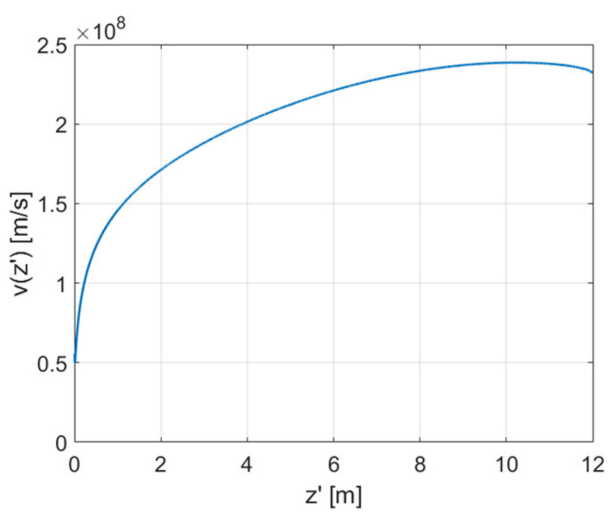

Fig. 25. Propagation speed as a function of height.

a fixed frequency of $5 \mathrm{MHz}$. The results clarify that, with the proposed antenna structure, the return stroke model that best represents the simulation results is characterized by a constant attenuation function (i.e., in the TL model) and a propagation speed increasing with the height. It is also worth noting that similar behavior is obtained for other frequencies in the range $0.5-50 \mathrm{MHz}$

\section{REFERENCES}

[1] C. A. Nucci and F. Rachidi, "Interaction of electromagnetic fields with electrical networks generated by lightning," in The Lightning Flash: Physical and Engineering Aspects. IEE Press, 2003, Ch. 8.

[2] V. Cooray, "Attachment of lightning flashes to grounded structures," in Lightning Electromagnetics, C. Vernon, Ed. London. U.K.: IET, 2012, pp. 765-787.

[3] V. Cooray, F. Rachidi, and M. Rubinstein, "Formulation of the field-totransmission line coupling equations in terms of scalar and vector potentials," IEEE Trans. Electromagn. Compat., vol. 59, no. 5, pp. 1586-1591, Oct. 2017.

[4] A. Piantini, "Extension of the rusck model for calculating lightninginduced voltages on overhead lines considering the soil electrical parameters," IEEE Trans. Electromagn. Compat., vol. 59, no. 1, pp. 154-162, Feb. 2017.

[5] F. Rachidi, "A review of field-to-transmission line coupling models with special emphasis to lightning-induced voltages on overhead lines," IEEE Trans. Electromagn. Compat., vol. 54, no. 4, pp. 898-911, Aug. 2012.

[6] A. K. Agrawal, H. J. Price, and S. H. Gurbaxani, "Transient response of multiconductor transmission lines excited by a nonuniform electromagnetic," IEEE Trans. Electromagn. Compat., vol. EMC-22, no. 2, pp. 119-129, May 1980.

[7] A. Andreotti, A. Pierno, and V. A. Rakov, "A new tool for calculation of lightning induced voltages in power system-Part I: Development of circuit model," IEEE Trans. Power Del., vol. 30, no. 1, pp. 326-333, Feb. 2015

[8] A. Andreotti, A. Pierno, and V. A. Rakov, "A new tool for calculation of lightning-induced voltages in power systems-Part II: Validation study," IEEE Trans. Power Del., vol. 30, no. 1, pp. 334-341, Feb. 2015.

[9] H. D. Hoidalen, "Lightning-induced overvoltages in low-voltage systems," Ph.D. Dissertation, Dept. Elect. Eng., Norwegian Univ. Sci. Technol., Trondheim, Norway, 1997.

[10] H. K. Hoidalen, "Analyitical formulation of lightning-induced voltages on multiconductor overhead lines above lossy ground," IEEE Trans. Electromagn. Compat., vol. 45, no. 1, pp. 92-100, Feb. 2003.

[11] H. K. Hoidalen, "Calculation of lightning induced overvoltages in MODELS including lossy ground effects," in Proc. Int. Conf. Power Syst. Transients, New Orleans, LA, USA, 2003.

[12] F. Napolitano, A. Borghetti, C. A. Nucci, and M. Paolone, "An advanced interface between the LIOV code and the EMPT-RV," in Proc. 29th Conf. Lightning Protection, Uppala, Sweden, 2008.

[13] A. De Conti, E. Perez, E. Soto, H. Silveira, S. Visacro, and H. Torres, "Calculation of lightning induced voltages on overhead distribution lines including insulation breakdown," IEEE Trans. Power Del., vol. 25, no. 4 pp. 3078-3084, Oct. 2010.
[14] M. Paolone, E. Perez, A. Borghetti, A. C. Nucci, F. Rachidi, and H. Torres, "Comparison of two computational programs for the calculation of lightning induced voltages on distribution systems," in Proc. 6th Int. Conf. Power Syst. Transients, Montreal, QC, Canada, 2005.

[15] A. Borghetti, J. A. Gutierrez, A. C. Nucci, M. Paolone, E. Petrache, and F. Rachidi, "Lightning-induced voltages on complex distribution systems: Models, advanced software tools, and experimental validation," J. Electrostatics, vol. 60, pp. 163-174, 2004.

[16] C. A. Nucci, M. Paolone, and F. Rachidi, "A new finite difference time domain scheme for the evaluation of lightning-induced overvoltage on multiconductor overhead lines," in Proc. Int Conf. Power Syst. Transients, Rio De Janiero, Brazil, 2001.

[17] C. A. Nucci and F. Rachidi, "Interaction of electromagnetic fields with electrical networks generated by lightning," in The Lightning Flash. London, U.K.: IET, 2014, pp. 559-610.

[18] M. Paolone, "Modeling of Lightning-induced voltages on distribution networks for the solution of power quality problems, and relevant implementation in a tranisent program," Ph.D. Thesis, Dept. Elect. Eng., Univ. Bologna, Bologna, Italy, 2002.

[19] A. Piantini, J. M. Janiszewski, A. Borghetti, C. A. Nucci, and M. Paolone, "A scale model for the study of the LEMP response of complex power distribution networks," IEEE Trans. Power Del., vol. 22, no. 1, pp. 710-720, Jan. 2007.

[20] M. Paolone et al., "Lightning electromagnetic field coupling to overhead lines: Theory, numerical simulations, and experimental validation," IEEE Trans. Electromagn. Compat., vol. 51, no. 3, pp. 532-547, Aug. 2009.

[21] M. Brignone, F. Delfino, R. Procopio, M. Rossi, and F. Rachidi, "Evaluation of power system lightning performance, Part I: Model and numerical solution using the PSCAD-EMTDC platform," IEEE Trans. Electromagn. Compat., vol. 59, no. 1, pp. 137-145, Feb. 2017.

[22] I. P.-E. V. Manitoba HVDCResearch Centre, "The professional's tool for electromagnetic transients simulation,” I. P.-E. V. Manitoba HVDCResearch Centre, Winnipeg, MB, Canada, 2008.

[23] M. Brignone, F. Delfino, R. Procopio, M. Rossi, and F. Rachidi, "Evaluation of power system lightning performance-Part II: Application to an overhead distribution network," IEEE Trans. Electromagn. Compat., vol. 59, no. 1, pp. 146-153, Feb. 2017.

[24] I. Bendato, M. Brignone, F. Delfino, R. Procopio, and F. Rachidi, "A methodology to reduce the computational effort in the evaluation of the lightning performance of distribution networks," Atmosphere, vol. 7 , p. 147, 2016.

[25] A. Piantini and J. M. Janiszewski, "Scale models and their application to the study of lightning transients in power systems," in Lightning Electromagnetics. London, U.K.: Institution of Engineering and Technology, 2012, pp. 719-764.

[26] C. A. Balanis, Antenna Theory: Analysis and Design. Hoboken, NJ, USA: Wiley, 2005.

[27] A. Piantini and J. M. Janiszewski, "Lightning-induced voltages on overhead lines-Application of the extended rusck model," IEEE Trans. Electromagn. Compat., vol. 51, no. 3, pp. 548-558, Aug. 2009.

[28] A. Piantini and J. M. Janiszewski, "The use of shield wires for reducing induced voltages from lightning electromagnetic fields," Electric Power Syst. Res., vol. 94, pp. 46-53, 2013.

[29] M. A. Uman and D. K. McLain, "Magnetic field of lightning return stroke," J. Geophysical Res., vol. 74, pp. 6899-6910, 1969.

[30] A. Shoory, F. Rachidi, M. Rubinstein, R. Moini, and S. H. H. Sadeghi, "Why do some lightning return stroke models not reproduce the far-field zero crossing?," J. Geophysical Res., Atmos., vol. 114, pp. 22-31, 2009.

[31] A. Shoory, F. Rachidi, M. Rubinstein, R. Moini, and S. H. H. Sadeghi, "Analytical expressions for zero-crossing times in lightning return-stroke engineering models," IEEE Trans. Electromagn. Compat., vol. 51, no. 4, pp. 963-974, Nov. 2009.

[32] G. J. Burke and A. J. Poggio, Numerical Electromagnetic Code (NEC)Method of Moments. A User-Oriented Computer Code for Analysis of the Electromagnetic Response of Antennas and Other Metal Structures. Part I. Program Description-Theory. Part II. Program Description-Code. Volume 1. Revised. Naval Ocean Systems Center San Diego, CA, USA: Defense Technical Information Center, 1977.

Authors' photographs and biographies not available at the time of publication. 